\title{
Efficacy of Ramosetron in Preventing Postoperative Nausea and Vomiting: An Updated Meta-analysis with Trial Sequential Analysis
}

\author{
Ayako Yokoi ${ }^{1}$, Takahiro Mihara ${ }^{1}, K_{\text {Koui Ka}}{ }^{1}$, Takahisa Goto ${ }^{2}$ \\ 1.Department of Anesthesiology, Kanagawa Children's Medical Center
}

2.Department of Anesthesiology and Critical Care Medicine, Yokohama City University Graduate School of Medicine

\section{BACKGROUND}

In 2013, we reported a meta-analysis on efficacy of ramosetron in preventing postoperative nausea and vomiting (PONV). Since then, several randomized controlled trials (RCTs) on the effects of ramosetron have been published. The aim of this study was to update the meta-analysis by using trial sequential analysis (TSA).

\section{METHODS}

\section{Search target:}

MEDLINE, CENTRAL, Embase,

Web of Science

\section{Inclusion criteria:}

RCTs that reported the efficacy of ramosetron for preventing PONV compared with placebo

\section{Outcome:}

early PON, POV, late PON, POV

(early $=0-6$ hours $/$ late $=6-24$ hours, $\mathrm{PON}=$ postoperative nausea $/ \mathrm{POV}=$ postoperative vomiting)

\section{RESULTS}

Out of 352 articles initially searched, 20 articles (2003 patients) had met the eligible criteria.

\section{(1) Summary}

\begin{tabular}{cc} 
& $\mathrm{N}$ \\
\hline early PON & 1419 \\
early POV & 1481 \\
late PON & 1419 \\
late POV & 1481 \\
\hline Fig.1 TSA of early PON \\
\hline Cumulative
\end{tabular}

\footnotetext{
Z score
}

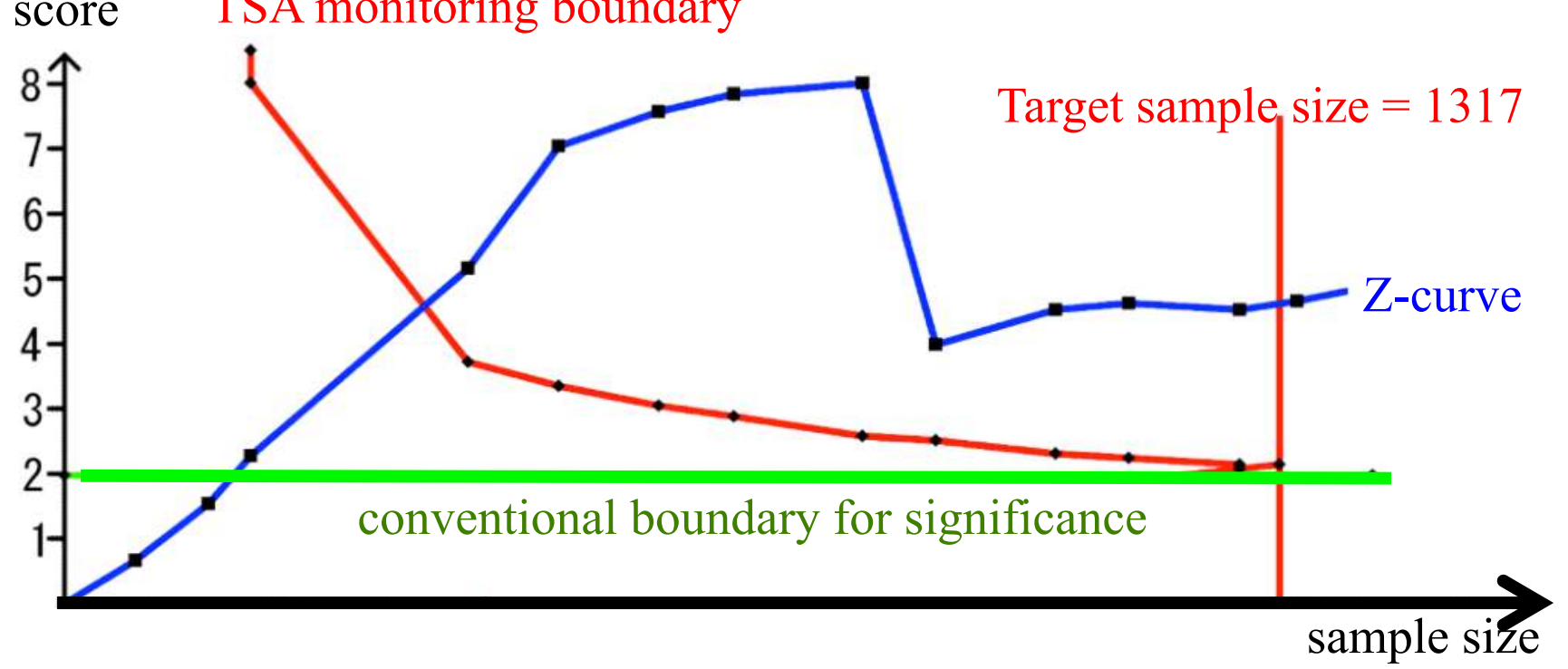

- Conventional random-effects meta-analysis showed that ramosetron was more effective than placebo for preventing PON and POV in both early and late periods.

- Heterogeneity $\left(\mathrm{I}^{2}>50 \%\right)$ observed in the early and late PON was reduced when restricted to double-blind RCTs.

-In all outcomes, the $\mathrm{Z}$ curve crossed the TSA monitoring boundary and reached the target sample size. It means that no additional trials are needed.
(2) Sensitivity analysis

$\mathrm{N}$

814

878

814

878

$\begin{array}{cc}\mathrm{RR}[95 \% \mathrm{CI}] & \mathrm{I}^{2} \\ 0.58[0.46 ; 0.72] & 10 \% \\ 0.39[0.25 ; 0.62] & 23 \% \\ 0.61[0.46 ; 0.82] & 36 \% \\ 0.46[0.29 ; 0.72] & 16 \%\end{array}$

Fig.2 Explanation of TSA diagram number of patients

(3) TSA

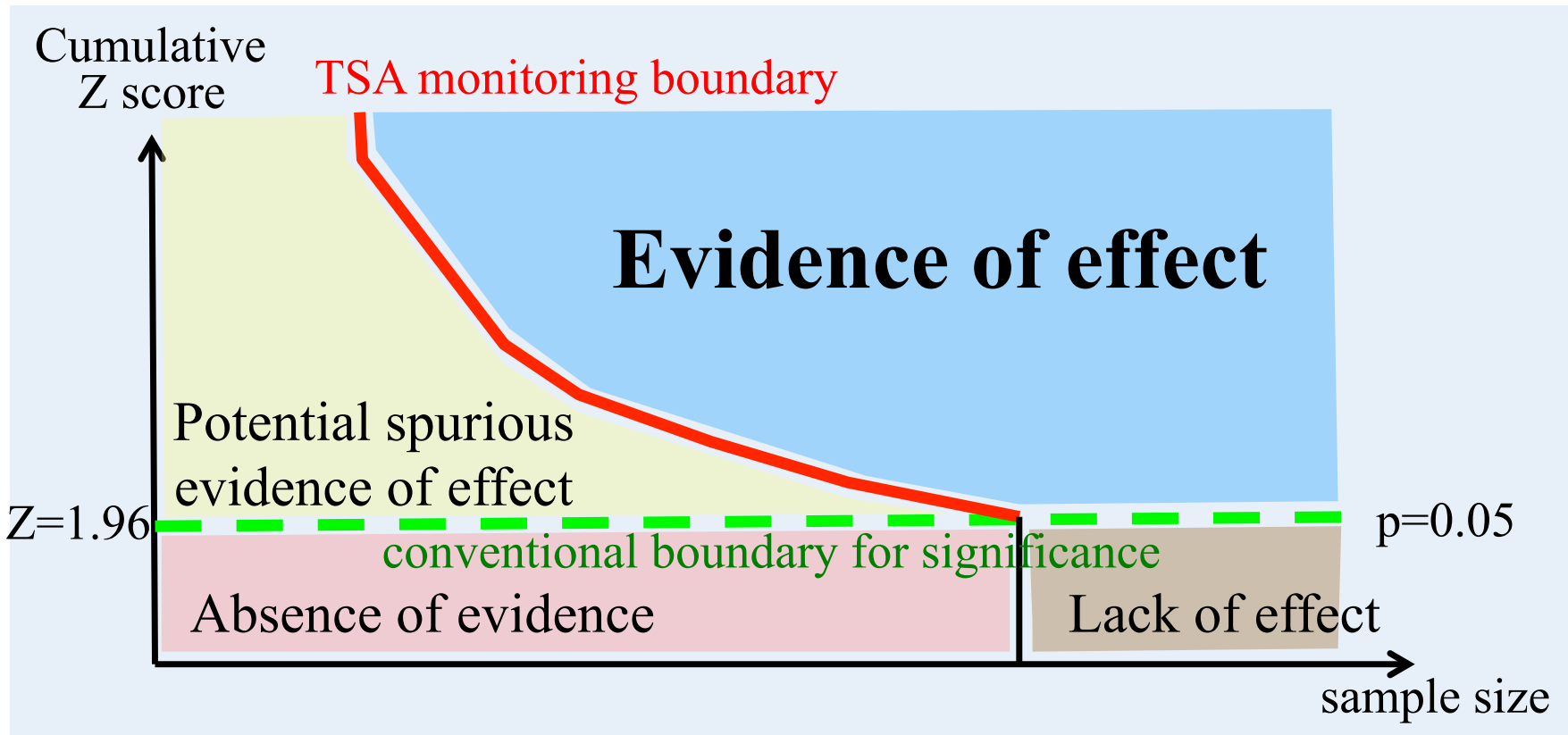

- Conventional boundary for significance (green) : $\mathrm{p}=0.05, \mathrm{Z}=1.96$

- TSA monitoring boundary (red) : adjust the p-value that is required for obtaining a statistical significance according to the

- Z curve : constructed with each cumulative Z-score calculated after including a new trial according to publication date

If the $\mathrm{Z}$ curve crosses the TSA monitoring boundary, it means that it is a reliable evidence, adjusting false positive error risk.

\section{CONCLUSION}

The efficacy of ramosetron is strong enough to lead to the conclusion that ramosetron reduces PONV compared with placebo, and thus there is no need for additional RCTs. 